\title{
STRESS URINARY INCONTINENCE DURING PREGNANCY IN PRIMIGRAVIDAE AND THEIR QUALITY OF LIFE
}

\author{
Gizem BORA ALKAN ${ }^{1}$, Ayten DiNÇ⿻2*
}

\author{
${ }^{1}$ Istinye University, Vocational School Health Care Services, Operating Room Services, 34010, Istanbul, Turkey \\ ${ }^{2}$ Canakkale Onsekiz Mart University, Faculty of Health Science, Department of Midwifery, 17020, Canakkale, Turkey
}

\begin{abstract}
This research was performed to determine the risk factors causing stress urinary incontinence (SUI) and its effect on quality of life during pregnancy in primigravidae. The study is a cross-sectional study conducted with 324 primigravidae who were followed up in the antenatal outpatient clinics. Incontinence quality of life scale (I-QoL) questionnaire exploring the risk factors for SUI was used as the principle data collection tool. The prevalence of SUI during pregnancy was 38.6\% (125/324). Multivariate analysis; maternal UI $(\mathrm{OR}=2.9,95 \% \mathrm{CI}: 1.5-5.5)$, sister having UI (OR $=5.6,95 \% \mathrm{CI}: 1.5-20)$, gestational DM (OR $=3.3,95 \% \mathrm{CI}: 1.2-8.6)$, pre-pregnancy BMI $(\mathrm{OR}=1.08,95 \% \mathrm{CI}: 1.0-1.1)$, smoking (OR $=4.3,95 \% \mathrm{CI}: 1.8-10.2)$, constipation (often) (OR $=6.2,95 \% \mathrm{CI}: 2.2-17)$ were determined as risk factors for SUI. It was determined that SUI during pregnancy affects the quality of life of women slightly. According to the results of this study, SUI is a common condition during pregnancy in primigravida. The findings will increase the awareness of healthcare professionals about SUI and contribute to the design of programs for the prevention of urinary incontinence during antenatal period.
\end{abstract}

Keywords: Pregnancy, Stress urinary incontinence, Quality of life

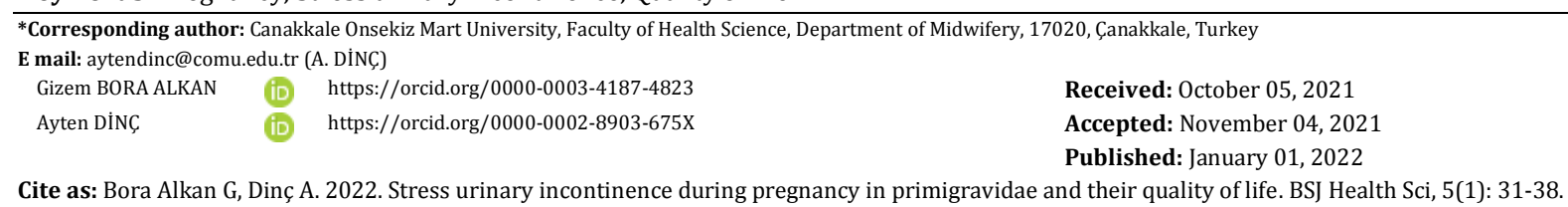

\section{Introduction}

Stress urinary incontinence (SUI) is defined as involuntary incontinence during daily activities that increase intra-abdominal pressure, such as coughing, laughing, sneezing, standing up suddenly, or lifting heavy objects and it is the most common type in pregnant women (Allahdin and Kambhampati, 2012; Sangsawang and Sangsawang, 2013).

During pregnancy many anatomical and physiological changes occur in the urinary system. Pregnancy and vaginal delivery are accepted to be important risk factor in the development of SUI, as pregnancy and childbirth may cause damage to neuromuscular and connective tissues structures supporting and controlling the bladder neck and urethra (Fitzgerald and Graziano, 2007; Weidner et al., 2009). While the prevalence of SUI increases due to the increase in the pressure of the enlarged uterus on the bladder during pregnancy, it is reported that it decreases after delivery (Adaji et al., 2010).

In the literature, the prevalence of SUI in primigravidae is $30 \%$ (26.3\%-34.3\%), and it increases with gestational age (Diez-Itza et al., 2009; Abdullah et al., 2016). Many factors have been found to be related with the development of SUI during pregnancy. These have been reported as genetic characteristics, maternal age, obesity, smoking, constipation, pre-pregnancy UI, recurrent urinary infection (Diez-Itza et al., 2009; Zhu et al., 2012;
Abdullah et al., 2016; Dinç, 2018). SUI can be reduced in pregnant women who use pelvic floor exercises and preventive strategies (Dinç et al., 2009).

It is reported that the quality of life among pregnant women with SUI complaints is negatively affected. Because it is an unpleasant, stressful condition that limits women's activities, leading, in numerous cases, to social isolation. For example, in a study of Dolan et al. (2004), it was reported that a negative effect on quality of life can be seen in approximately $54.3 \%$ of pregnant women. On the other hand Kocaöz et al. (2010), reported that $70.8 \%$ of pregnant women had a negative effect on their quality of life. In addition, studies have shown that frequent and excessive urinary incontinence during pregnancy reduces the quality of life (Demircan et al., 2016; Kök et al., 2016). However, it is thought that urinary incontinence, which is common during pregnancy, will pass in the postpartum period and few women seek for help (Demir and Kızlkaya Beji, 2015; Balık et al., 2016). For this reason, women should be monitored regularly to prevent or reduce the frequency of incontinence during pregnancy and at postpartum period.

While there are many studies in the literature on urinary incontinence in women, there are limited studies on SUI risk factors and quality of life in primigravidae (Dolan et al., 2004; Allahdin and Kambhampati, 2012; Abdullah et al., 2016). In Turkey, there is no study on urinary incontinence in primigravidae. Nurses are an important 
member of the multidisciplinary team from which pregnant women receive services with their roles as consultant, educator and caregiver. In this respect, understanding urinary incontinence in women will contribute to the planning of preventive nursing interventions. This research was performed to determine the risk factors causing stress urinary incontinence (SUI) and its effect on quality of life during pregnancy in primigravidae. By this way, it is aimed to raise awareness of SUI in women during gestation and to motivate pregnant women about prevention, applying to health institutions and seeking treatment.

\subsection{Study questions}

1. What is the prevalence of SUI during pregnancy in primigravidae?

2. What are the risk factors affecting SUI during pregnancy in primigravidae?

3. Does SUI affect quality of life in primigravidae?

\section{Material and Methods}

A cross-sectional study was conducted between October 2015 and June 2016 with primigravidae of 28 weeks or more followed in antenatal outpatient clinics of a public hospitals in Canakkale, Turkey. In order to determine at what trimester SUI starts during pregnancy, pregnant women in the last trimester were selected. Among the criteria for inclusion in this study; 28 weeks and over gestation, primigravidae, willingness to participate in the study can be counted. On the other hand, exclusion criteria include genito-urinary system pathology and urinary infection.

In order to define SUI according to the ICS (International Continence Association) protocol; primigravidae with complaints of involuntary urinary incontinence during coughing, sneezing, laughing, straining and other physical activities that increase intra-abdominal pressure were evaluated as having SUI. In the literature, the frequency of SUI in primigravidae is reported to be $30 \%$ on average (Diez-Itza et al., 2009). The sample size was determined as 323 individuals by using an acceptable error of $5 \%$, 95\% confidence level and the sample calculation.

Data were collected by the individual information form and Incontinence Quality of Life Scale (I-QoL). The data collection of the study was carried out face-to-face by the researcher on a voluntary basis, 1-2 days a week for an average of 15 minutes, at a time when the individuals were available in antenatal outpatient clinics during institutional permits.

Individual information form, prepared in line with the literature consists of 22 questions including the following features; socio-demographic characteristics of pregnant women (age, education level, income status, employment status and health, BMI), information about pregnancy (gestational week, gestational diabetes mellitus), personal habits (smoking, caffeinated beverage intake, constipation, status of making pelvic floor muscle exercises (PFME), fluid intake, number of urination) and uro-gynecological history (UI complaint, urinary incontinence frequency and amount) (Wesnes et al., 2007; Allahdin and Kambhampati 2012; Zhu et al., 2012).

Incontinence Quality of Life Scale (I-QoL), which was generated by Wagner et al. (1996), the European version was created by Patrick et al. (1999), and the validity and reliability in Turkish by Özerdoğan and Kızllkaya Beji (2003) consists of three sub-dimensions (Wagner et al., 1996; Patrick et al., 1999; Özerdoğan and Kızılkaya Beji, 2003). These include; limitation of behaviors, psychosocial influence and social isolation. The scale is 5 point Likert type "1-very much", "2-pretty much", "3moderate", "4-a little", "5-not at all", the final total score was converted into a scale value from 0 to 100 in order to be understood better. The higher scores on the scale indicate a better quality of life. The Cronbach Alpha coefficient for the Turkish reliability of the scale was 0.96 by Özerdoğan and Kızılkaya Beji (2003), and the Cronbach Alpha reliability coefficient was determined as 0.91 in this study.

Number Cruncher Statistical System (NCSS) (2007, Kaysville, Utah, USA) program was used for statistical analysis. The evaluation of the data used that percentage distribution mean, variance, Mann Whitney U test, Kruskal Wallis test (Önder, 2018), One-way ANOVA, Pearson's correlation analysis. As a multivariate analysis; the effects of other risk factors on urinary incontinence were evaluated using Backward (Conditional) Logistic Regression analysis. Significance was evaluated at the $\mathrm{P}<$ 0.05 level.

\section{Results}

Table 1 shows the distribution of data on stress urinary incontinence in primigravidae. The prevalence of SUI during pregnancy is $38.6 \%$ and urinary incontinence problem of $2.8 \%$ began before pregnancy. When the SUI complaint is examined according to trimesters; it started in the first trimester in $16 \%$, in the second trimester in $42.4 \%$ and in the third trimester in $41.6 \%$. While $12.8 \%$ of pregnant women stated that they had urinary incontinence more than once a day, $24.8 \%$ had once a month. $38.4 \%$ of pregnant women have moderate urinary incontinence and $24.8 \%$ use pads for urinary incontinence. When the activities of pregnant women during urinary incontinence were examined; sneezing (60.8\%), coughing (52.8\%), physical activity (36.8\%) were the top activities reported. In this study, there was no difference between women continent and incontinent in terms of age, education, employment status, income, health insurance $(\mathrm{P}>0.05)$. The rate of SUI complaints was higher in those who were overweight and obese before and during pregnancy $(\mathrm{P}<0.05)$. In those whose mother and sister complained of urinary incontinence, the rate of SUI was found to be higher $(\mathrm{P}<0.01)$. SUI was more common in those with gestational diabetes mellitus (DM) $(\mathrm{P}<0.01)$. SUI was higher in smokers, patients with constipation and patients who consume 1-2 cups of caffeinated beverages per day $(\mathrm{P}<0.05)$ (Table 2$)$. 
Table 1. Distribution of data regarding stress urinary incontinence in primigravidae

\begin{tabular}{|c|c|c|}
\hline Variables & $\mathrm{n}$ & $\%$ \\
\hline \multicolumn{3}{|l|}{ Pre-pregnancy SUI (n=324) } \\
\hline Yes & 9 & 2.8 \\
\hline No & 315 & 97.2 \\
\hline \multicolumn{3}{|l|}{ SUI during pregnancy $(n=324)$} \\
\hline Yes & 125 & 38.6 \\
\hline No & 199 & 61.4 \\
\hline \multicolumn{3}{|l|}{ SUI by trimesters $(n=125)$} \\
\hline First trimester & 20 & 16 \\
\hline Second trimester & 53 & 42.4 \\
\hline Third trimester & 52 & 41.6 \\
\hline \multicolumn{3}{|l|}{ SUI frequency $(n=125)$} \\
\hline Once a day & 17 & 13.6 \\
\hline 2 and over a day & 16 & 12.8 \\
\hline Once a week or less & 22 & 17.6 \\
\hline 2-4 times a week & 24 & 19.2 \\
\hline Once a month & 31 & 24.8 \\
\hline 2-4 times a month & 15 & 12.0 \\
\hline \multicolumn{3}{|l|}{ Using pad $(n=125)$} \\
\hline Yes & 31 & 24.8 \\
\hline No & 94 & 75.2 \\
\hline \multicolumn{3}{|l|}{ The amount of incontinence $(n=125)$} \\
\hline Small (Few drops) & 70 & 56.0 \\
\hline Moderate (moistness of pad or clothes) & 48 & 38.4 \\
\hline Large (wetness of pad or clothes) & 7 & 5,6 \\
\hline \multicolumn{3}{|l|}{ Urinary incontinence features* } \\
\hline Cough & 66 & 52.8 \\
\hline Sneeze & 76 & 60.8 \\
\hline Laugh & 12 & 31.2 \\
\hline Getting out of bed & 9 & 7.2 \\
\hline Climbing Stairs & 11 & 8.8 \\
\hline Removing Something & 27 & 21.6 \\
\hline Physical Activity & 46 & 36.8 \\
\hline Sexual intercourse & 4 & 3.2 \\
\hline
\end{tabular}

SUI= stress urinary incontinence, ${ }^{*}$ more than one answer was given.

When the factors affecting stress urinary incontinence are examined by logistic regression in Table 3; having UI complaints in her mother (OR $=2.9,95 \% \mathrm{CI}: 1.5-5.5)$, having UI complaints in her sister (OR $=5.6,95 \% \mathrm{CI}: 1.5$ 20.3), having gestational DM (OR $=3.3,95 \% \mathrm{CI}: 1.2-8.6)$, smoking $(\mathrm{OR}=4.3,95 \%$ CI:1.8-10.2), higher prepregnancy BMI $\quad(\mathrm{OR}=1.08,95 \% \mathrm{CI}: 1.0-1.2)$, occasional constipation $(\mathrm{OR}=2.2,95 \%$ CI:1.1-4.2), frequent constipation (OR $=6.2,95 \% \mathrm{CI}: 2.3-17.0$ ) were found to be risk factors for SUI.

Pregnant women had an average score of $59.58 \pm 23.00$ (0-100) from I-QoL scale "Limitation of Behaviors" subdimension, $87.20 \pm 17.39 \quad(5.56-100)$ from the
"Psychosocial Impact" sub-dimension, 79.16 \pm 20.70 (0100) from "Social Isolation" "sub-dimension and $75.33 \pm 17.36(4.55-98.86)$ as total scale score.

In Table 4, the comparison of the incontinence quality of life sub-dimension and total score averages of pregnant women according to trimesters, frequency and amount of urinary incontinence is included. The quality of life scores of pregnant women were $74.83 \pm 17.02$ in the first trimester, $77.77 \pm 17.78$ in the second trimester, and $74.15 \pm 17.83$ in the third trimester, no significant difference between the total scores of life quality and sub-dimensions between trimesters $(\mathrm{P}<0.05)$ was observed. 
When life quality scores of gravid in terms of urinary incontinence frequency is compared; those whose urinary incontinence frequency was once or several times a month had higher life quality scores than those whose frequency of urinary incontinence was several times a day or a week in terms of limitation of behaviors sub-dimension, psychosocial influence sub-dimension; social isolation sub-dimension, total score and there was a statistically significant difference between them $(\mathrm{P}<$ $0.05)$.
Pregnant women with a few drops of urinary incontinence were found to have higher quality of life scores in terms of limitation of behaviors sub-dimension, social isolation sub-dimension, total score when compared with pregnant women who have enough urinary incontinence to wet their underwear $(\mathrm{P}<0.05)$. There was no significant relationship between the amount of urinary incontinence and the psychosocial impact sub-dimension $(\mathrm{P}>0.05)$.

Table 2. Primigravidae socio-demographic, obstetric and urogynecological features in terms of their urinary incontinence complaints

\begin{tabular}{|c|c|c|c|c|}
\hline & & $\begin{array}{l}\text { SUI }(+) \\
(n=125)\end{array}$ & $\begin{array}{c}\text { SUI }(-) \\
(n=199)\end{array}$ & $P$ \\
\hline \multirow{3}{*}{ Age (years) } & Mean \pm SD & $27.34 \pm 4.66$ & $26.47 \pm 4.33$ & \multirow{2}{*}{ a 0.089} \\
\hline & Min-Max (median) & $18-38(28)$ & $18-40(26)$ & \\
\hline & & $\mathrm{n}(\%)$ & $\mathrm{n}(\%)$ & \\
\hline \multirow{3}{*}{ Education Status } & Primary education & $18(14.4)$ & $27(13.6)$ & \multirow{3}{*}{ c0.452 } \\
\hline & High school & $35(28)$ & $69(34.7)$ & \\
\hline & University & $72(57.6)$ & $103(51.8)$ & \\
\hline \multirow{2}{*}{ Employment status } & Employed & $53(42.4)$ & $88(44.2)$ & \multirow[t]{2}{*}{$\mathrm{d} 0.419$} \\
\hline & Unemployed & $72(57.6)$ & $111(55.8)$ & \\
\hline \multirow[t]{3}{*}{ Family income status } & High & $39(31.2)$ & $67(33.7)$ & \multirow[t]{3}{*}{ e0.687 } \\
\hline & Moderate & $85(68)$ & $128(64.3)$ & \\
\hline & Low & $1(0.8)$ & $4(2)$ & \\
\hline \multirow{3}{*}{ Health Assurance } & Yes & $122(97.6)$ & 197 (99) & \multirow{3}{*}{$\mathrm{d} 0.378$} \\
\hline & No & $3(2.4)$ & $2(1.0)$ & \\
\hline & Normal Weight (18.5-24.9) & $10(8.0)$ & $35(17.6)$ & \\
\hline \multirow[t]{2}{*}{ Pre-Pregnancy BMI } & Overweight (25-29.9) & $82(65.6)$ & $144(72.4)$ & \multirow[t]{2}{*}{${ }^{c} 0.001^{* *}$} \\
\hline & Obese $(\geq 30.0)$ & $33(26.4)$ & $20(10.1)$ & \\
\hline \multirow{2}{*}{ BMI during pregnancy } & Overweight (25-29.9) & $39(31.2)$ & $91(45.7)$ & \multirow{2}{*}{ c0.009** } \\
\hline & Obese $(\geq 30.0)$ & $86(68.8)$ & $108(54.3)$ & \\
\hline \multirow{2}{*}{ UI in her mother } & Yes & $58(46.4)$ & $34(17.1)$ & \multirow[t]{2}{*}{${ }^{c} 0.001^{* *}$} \\
\hline & No & 67 (53.6) & 165 (82.9) & \\
\hline \multirow{2}{*}{ UI in her sister } & Yes & $21(16.8)$ & $4(2.0)$ & \multirow{2}{*}{${ }^{c} 0.001^{* *}$} \\
\hline & No & $104(83.2)$ & 195 (98.0) & \\
\hline \multirow{2}{*}{ Gestational DM } & Yes & $26(20.8)$ & $9(4.5)$ & \multirow[t]{2}{*}{ c0.001** } \\
\hline & No & $99(79.2)$ & $190(95.5)$ & \\
\hline \multirow{2}{*}{ Smoking } & Yes & $21(16.8)$ & $15(7.5)$ & \multirow[t]{2}{*}{$\mathrm{c} 0.010^{* *}$} \\
\hline & No & $104(83.2)$ & $184(92.5)$ & \\
\hline \multirow{3}{*}{$\begin{array}{l}\text { Caffeinated Drink (cup- } \\
\text { day) }\end{array}$} & 1-2 cups & 77 (61.6) & $86(43.2)$ & \multirow{3}{*}{${ }^{c} 0.004^{* *}$} \\
\hline & $\geq 3$ Cup & $19(15.2)$ & 38 (19.1) & \\
\hline & No & $29(23.2)$ & 75 (37.7) & \\
\hline \multirow{4}{*}{ Constipation } & Often & $22(17.6)$ & $8(4.0)$ & \multirow{4}{*}{${ }^{c} 0.001^{* *}$} \\
\hline & Sometimes & 36 (28.8) & 35 (17.6) & \\
\hline & Rarely & $16(12.8)$ & $20(10.1)$ & \\
\hline & No & $51(40.8)$ & $136(68.3)$ & \\
\hline
\end{tabular}

SUI= stress urinary incontinence, BMI= body mass index, DM: diabetes mellitus, $\mathrm{SD}=$ standard deviation, Min= minimum, Max= maximum, $a=$ Student-t test, $\mathrm{c}=$ Pearson Chi-Square test, $\mathrm{d}=$ Fisher's exact test, $\mathrm{e}=$ Fisher Freeman Halton test. 
Black Sea Journal of Health Science

Table 3. Risk factors of SUI in primigravidae, multivariate analyses

\begin{tabular}{lcccc}
\hline & P & Odds ratio & \multicolumn{2}{c}{$95 \%$ CI } \\
& & & Lower & Upper \\
\hline UI complaint in mother (reference: yes) & $0.001^{* *}$ & 2.9 & 1.5 & 5.5 \\
Sister UI complaint (reference: yes) & $0.009^{* *}$ & 5.6 & 1.5 & 20.3 \\
Gestational Diabetes Mellutus & $0.013^{*}$ & 3.3 & 1.2 & 8.6 \\
(reference: yes) & & & 1.8 & 10.2 \\
Smoking (reference: yes) & $0.001^{* *}$ & 4.3 & 1.08 & 1.0 \\
Pre-Pregnancy BMI & $0.020^{*}$ & 2.2 & 1.1 & 4.2 \\
Constipation (occasional) & $0.024^{*}$ & 6.2 & 2.3 & 17.0 \\
Constipation (Frequent) & $0.001^{* *}$ & 6.2 & \\
\hline
\end{tabular}

SUI= stress urinary incontinence, $\mathrm{UI}=$ urinary incontinence, BMI= body mass index.

Table 4. Comparison of I-QoL scale scores of primigravidae according to trimesters, frequency and amount of urinary incontinence

\begin{tabular}{|c|c|c|c|c|}
\hline \multirow{3}{*}{ SUI feature } & \multicolumn{4}{|c|}{ I-QoL scale scores } \\
\hline & Limitation of Behavior & $\begin{array}{c}\text { Psychosocial } \\
\text { Affection }\end{array}$ & Social Isolation & Total Score \\
\hline & Mean \pm SD & Mean \pm SD & Mean \pm SD & Mean \pm SD \\
\hline \multicolumn{5}{|l|}{ SUI start time } \\
\hline 1. Trimester $(n=20)$ & $57.97 \pm 21.45$ & $87.92 \pm 16.65$ & $78.25 \pm 21.84$ & $74.83 \pm 17.02$ \\
\hline 2. Trimester $(n=53)$ & $65.8 \pm 21.57$ & $86.64 \pm 19.36$ & $80.94 \pm 21.06$ & $77.77 \pm 17.78$ \\
\hline 3. Trimester $(n=52)$ & $55.45 \pm 24.51$ & $87.86 \pm 16.47$ & $79.42 \pm 19.98$ & $74.15 \pm 17.83$ \\
\hline $\mathrm{P}$ & $\mathrm{h} 0.076$ & j0.638 & j0.860 & $\mathrm{j} 0.481$ \\
\hline \multicolumn{5}{|l|}{ UI frequency } \\
\hline Once a day $(n=17)$ & $59.01 \pm 22.31$ & $82.35 \pm 25.15$ & $75.59 \pm 24.23$ & $72.33 \pm 21.55$ \\
\hline $\begin{array}{l}\text { More than twice a day } \\
(n=16)\end{array}$ & $64.84 \pm 24.99$ & $83.16 \pm 14.47$ & $77.81 \pm 18.35$ & $75.28 \pm 17.05$ \\
\hline Once a week $(n=22)$ & $46.31 \pm 26.81$ & $79.17 \pm 25.54$ & $66.14 \pm 27.12$ & $64.26 \pm 23.47$ \\
\hline 2-4 times a week $(n=24)$ & $54.82 \pm 17.8$ & $90.97 \pm 9.84$ & $78.75 \pm 17.08$ & $75.05 \pm 11.65$ \\
\hline Once a month $(\mathrm{n}=31)$ & $69.56 \pm 20.49$ & $91.22 \pm 11.94$ & $90.48 \pm 14.91$ & $83.17 \pm 12.76$ \\
\hline $2-4$ times a month $(n=15)$ & $61.04 \pm 19.51$ & $94.44 \pm 4.92$ & $81 \pm 11.53$ & $79.24 \pm 8.57$ \\
\hline $\mathrm{P}$ & h $0.023^{*}$ & j0.028* & j0.001** & j0.014* \\
\hline \multicolumn{5}{|c|}{ The amount of urinary incontinence } \\
\hline Moderate $(n=70)$ & $64.02 \pm 20.30$ & $89.44 \pm 14.18$ & $85.14 \pm 17.63$ & $79.22 \pm 14.51$ \\
\hline Large $(n=48)$ & $53.92 \pm 25.11$ & $84.34 \pm 20.57$ & $71.55 \pm 21.94$ & $70.37 \pm 19.46$ \\
\hline $\mathrm{P}$ & a $0.014^{*}$ & b0.104 & b0.001** & b $0.005^{* *}$ \\
\hline
\end{tabular}

$\mathrm{I}-\mathrm{QoL}=$ incontinence quality of life scale, $\mathrm{SUI}=$ stress urinary incontinence, $\mathrm{SD}=$ standard deviation, $\mathrm{a}=$ Student-t test, $\mathrm{b}=$ Mann Whitney $\mathrm{U}$ test, $\mathrm{h}=$ Oneway Anova test, $\mathrm{j}=$ Kruskal Wallis test.

\section{Discussion}

The most common type of UI during pregnancy is stress urinary incontinence (Allahdin and Kambhampati, 2012). In the literature, the prevalence of SUI in pregnancy is between $18.6 \%$ and $75 \%$ (Sangsawang, 2014), while the prevalence of SUI in primigaravidas is reported between 26.3\%-35.6\% and its incidence increases in the second and third trimesters (Dolan et al., 2004; Diez-Itza et al., 2009; Abdullah et al., 2016). The pre-pregnancy rate of SUI was reported as $2.2 \%$ by Liang et al. (2012) and 3.5\% by Dolan et al. (2004). In our study, the prevalence of SUI during pregnancy was $38.6 \%$, and $2.8 \%$ of primigravidae had SUI complaints before pregnancy. In addition, SUI complaints of pregnant women started in the first trimester in $16 \%$, in the second trimester in $42.4 \%$ and in the third trimester in $41.6 \%$ of the patients. Liang et al. (2012) showed in their study that the prevalence of SUI in the first, second and third trimesters were 9.8\%, $13.9 \%$ and $26.7 \%$, respectively. Dinç (2018), reported the prevalence of SUI in the first, second and third trimesters were $29.7 \%, 32.2 \%$ and $52.1 \%$ respectively. This study results are consistent with the literature findings.

When studies investigating the frequency of urinary incontinence with the ICIQ-SF scale are examined in the literature; It has been reported that $31.2-42.9 \%$ of pregnant women have urinary incontinence at a frequency of once or more per day, and 57.1-68.8\% of them once or more per week (Kocaöz et al., 2010; Franco et al., 2014; Dinç, 2018). In this study, it was found that $26.4 \%$ of pregnant women had urinary incontinence one or more times a day, and $36.8 \%$ of pregnant women had urinary incontinence once a week or more.

When studies examining the amount of UI in pregnant women are examined; it is observed that $55.7-90.5 \%$ of 
pregnant women have urinary incontinence in small amounts, $9.5 \%-59.7 \%$ of them have medium/large amounts of urine incontinence (Kocaöz et al., 2010; Franco et al., 2014; Kök et al., 2016, Dinç, 2018). This study, when the amount of urinary incontinence of pregnant women is questioned, $56 \%$ of pregnant women answered the amount of UI as a few drops, $38.4 \%$ as wet/small amount and $5.6 \%$ as quite wet. This study, $24.8 \%$ of pregnant women with SUI complaints use a pad. In the literature, Kök et al. (2016) reported pad use rate in pregnant women as $32.8 \%$ and Dinç (2018) reported as $22.3 \%$. The study findings are compatible with the literature.

Most of the activities that pregnant women did during their SUI complaint include; sneezing, coughing, physical activity, laughing $(60.8 \%, 52.8 \%, 36.8 \%, 31.2 \%$, respectively). Studies have also reported that pregnant women mostly had complaint of urinary incontinence while coughing and sneezing (Kök et al., 2016; Gökalp et al., 2020).

Although urinary incontinence has been reported as a health problem seen at all ages, some studies have reported that the prevalence of UI is significantly higher in women aged 30 and over (Zhu et al., 2012; Kök et al., 2016; Dinç, 2018). In our study, the mean age of pregnant women with SUI complaints was $27.34 \pm 4.66$, and no relationship was found between maternal age and UI. In parallel with our work, Abdullah et al. (2016) and DiezItza et al. (2009), found no relationship between SUI and maternal age in their studies with primigravidae.

In some studies, the rate of UI is higher in people with low income (Liu et al. 2014; Özdemir et al., 2018). Contrary to these findings, no relationship was found between educational status, employment status and SUI in our study. Other studies also support our findings (Kocaöz et al., 2010; Kök et al., 2016).

Obesity causes chronic tension in the pelvic floor by increasing intra-abdominal pressure. This pressure disrupts the blood flow and nerve inervation to the bladder and urethra (Jain and Parsons, 2011). It also increases the pressure on the bladder. Thus, obesity is reported as the major risk factor contributing to SUI in women (Diez-Itza et al., 2009). In parallel with our study, Kök et al., (2016) and Dinç (2018) reported that the increase in BMI before pregnancy increases the prevalence of UI during pregnancy.

Among the etiological factors, genetic predisposition is known as an important risk factor. In our study, the rate of UI incidence in mothers and sisters of pregnant women with SUI complaints was found to be statistically significantly higher than pregnant women without SUI complaints. In parallel with our study, Kocaöz et al. (2010), stated the presence of UI in mother and sister as a risk factor for UI during pregnancy. Kök et al. (2016), reported that there is a relationship between having a family history of UI complaints and having UI during pregnancy.

In the literature, an increase in the incidence of UI in women with gestational DM has been reported (Ahmed et al., 2013; Dereli Yilmaz et al., 2016). Similarly, in our study it was found that gestational DM is associated with SUI complaint.

Due to the hard and frequent cough that develops in smokers, damage to the pelvic floor muscles and increase in abdominal pressure are observed. In addition to these, the development of UI is facilitated by the antiestrogenic effect of some chemicals in cigarettes and the disruption of collagen synthesis. There are some other studies reporting similar results (Martins, 2010; Ahmet et al., 2013; Özdemir et al., 2018), whereas some studies found no correlation between smoking and urinary incontinence (Liang et al., 2012).

It has been suggested that constipation may cause dysfunction in the pelvic muscles because of the stressrelated damage in the pelvic nerves (Zhu et al., 2012). In our study, it was found that constipation during pregnancy is associated with SUI complaint. There are other studies in parallel with our findings (Kocaöz et al., 2010; Zhu et al., 2012; Dinç, 2018).

This study, it was found that 1-2 cups of caffeinated beverage intake per day during pregnancy increased SUI complaints. Martin et al. (2010), reported similar findings with our study. Abdullah et al. (2016), found no relationship between the intake of caffeinated beverages during pregnancy and UI.

As a result of the logistic regression analysis; it was shown that presence of UI complaint in mother increases SUI risk by 2.9 times (95\% CI: 1.5-5.5), presence of UI complaint in sister increases SUI risk by 5.6 times (95\% CI: 1.5-20.3). In parallel with our study, Kocaöz et al. (2010) found in their study that presence of UI in mother increased IU complaint during pregnancy for about 1.5 times and presence of UI in sister increased IU complaint during pregnancy for 0.9 times.

In the present study, gestational DM was found to be a risk factor for SUI for 3.3 times (95\% CI: 1.2-8.6). Izci et al. (2009) SUI risk was reported to be 2.5 times more (95\% CI: 1.8-3.3) in women with DM.

In the present study, it was found that smoking increased the risk of SUI 4.3 times (95\% CI: 1.8-10.2). Liang et al. (2012) reported that pregnant women who have a smoking habit are at significantly higher risk for SUI during pregnancy than pregnant women who do not (OR=2.0; 95\% CI: 1.1-3.5).

Diez-Itza et al. (2009) it was reported that having a high BMI increases the risk of SUI 2 times (95\% CI: 1.09-3.99). Zhu et al. (2012) reported that high BMI icreases the risk of SUI 1.03 times (95\% CI: 1.02-1.05). In this study, it was found that having excess BMI before pregnancy increased the risk of SUI (OR=1.08; 95\% CI: 1.0-1.2).

Kocaöz et al. (2010) reported that constipation increased the risk of UI 4.1 times (OR $=4.1 ; 95 \%$ CI: 1.7-9.9). Dinç (2018), reported that pregnant women with constipation had a 3 -fold higher risk of developing an UI (OR = 3.1, 95\% CI: 1.7-5.6). In this study, occasional constipation was found as a risk factor that increased the risk of UI 2.2 
times (95\% CI: 1.1-4.2) and frequent constipation was found as a risk factor that increased the risk of UI 6.2 times (95\% CI: 2.3-17.0).

In the present study, it was found that the quality of life of primigravidae suffering from SUI was affected very little. Dolan et al. (2004) it has been reported that the symptoms of most primigravidae are mild and their quality of life is not affected. Abdullah et al. (2016) it has been stated that the daily life activities of primigravidae are not affected although most of them have urinary incontinence complaints. Our study is compatible with the literature findings.

There was no relationship between the time of onset of urinary incontinence and quality of life scores according to trimesters. In the present study is in line with the findings of the literature (Kök et al., 2016; Gökalp et al., 2020). This may be due to the fact that urinary incontinence during pregnancy is considered a temporary problem or a normal condition specific to pregnancy. Comparing life quality scores of gravid women according to urinary incontinence frequency, it has been determined that as the frequency of urinary incontinence increases, quality of life scores decrease. There are other studies in parallel with our findings (Kocaöz et al., 2010; Gökalp et al., 2020). In this study, those with wet urinary incontinence (enough to wet pads and underwear) scored lower in the sub-dimension of limiting behavior and social isolation, but no relationship was found between the sub-dimension of psychosocial involvement and the amount of urinary incontinence. This result may be due to the pregnant women thinking of urinary incontinence as a temporary condition specific to pregnancy.

The limitations of this study, SUI status was evaluated by taking into account women's self-report. Study data were collected from a public hospital in Çanakkale province. This situation restricts the generalizability of the study results.

\section{Conclusion}

As a result of this study, it was found that SUI complaints are common in primigravidae. Urinary incontinence in mother and sister of pregnant women, gestational DM, constipation, smoking, and obesity were found to be risk factors for SUI. In this study, it was determined that the quality of life of primigravidae suffering from SUI was affected very little. These results show that Turkish pregnant women do not care enough about SUI. They think that develops due to pregnancy or they perceive urinary incontinence as a normal or minör problem. In order to prevent or reduce the frequency of incontinence during pregnancy and postpartum period, women should be monitored regularly starting from the pregnancy. Detecting urinary incontinence at an early stage and addressing the problem by providing adequate counseling will contribute significantly to the improvement of women's health. In this context, nurses should be sensitive and trained about urinary incontinence. Preventing the development of urinary incontinence and taking an active role in the treatment of women who experience this problem are among the main responsibilities of nurses.

\section{Author Contributions}

All of the authors declare that they have all participated in the design, execution, and analysis of the paper, and that they have approved the final version.

\section{Conflict of Interest}

The authors declared that there is no conflict of interest.

\section{Ethical Approval/Informed Consent}

For this study, ethics approval was obtained from Canakkale Onsekiz Mart University Clinical Research Ethics Committee with decision no 2015/73 dated September 09, 2015. Our research was carried out in accordance with the Declaration of Helsinki of the World Medical Association. Written consent was obtained from the patients who participated in this study.

\section{Acknowledgements}

This study was produced from the master thesis.

\section{References}

Abdullah B, Ayub SH, Mohd Zahid AZ. 2016. Urinary incontinence in primigravida: the neglected pregnancy predicament. European J Obstetrics Gynecology and Reprod Biol, 198: 110-115.

Adaji SE, Shittu OS, Bature BS, Nasir S, Olatunji O. 2010. Suffering in silence: pregnant women's experience of urinary incontinence in Zaria, Nigeria. European J Obstetrics Gynecology and Reprod Biol, 150: 19-23.

Ahmed HM, Osman VA, Al-Alaf SK, Al-Tawil NG. 2013. Prevalence of urinary incontinence and probable risk factors in a sample of kurdish women. Sultan Qaboos Univ Med J, 13: 269-274.

Allahdin S, Kambhampati L. 2012. Stress urinary incontinence in continent primigravidae. J Obstet Gynaecol, 32: 2-5

Balık G, Güven ES, Tekin YB. 2016. Lower urinary tract symptoms and urinary incontinence during pregnancy. Lower Urinary Tract Symp, 8: 120-124.

Demir, S, Kızılkaya Beji N. 2015. Quality of life and health seeking behaviors of women with urinary incontinence. Florence Nightingale J Nurs, 23: 23-31.

Demircan N, Özmen Ü, Köktürk F. 2016. What are the probable predictors of urinary incontinence during pregnancy? Peer J, 4: e2283.

Dereli Yilmaz S, Demirgöz Bal M, Celik S. 2016. Lower urinary tract symptoms in women with type 2 diabetes mellitus. J Wound Ostomy Continence Nurs, 43: 523-528.

Diez-Itza I, Ibañez L, Arrue M. 2009. Influence of maternal weight on the new onset of stress urinary incontinence in pregnant women. Int Urogynecol J Pelvic Floor Dysfunct, 20: 1259-1263.

Dinç A, Kızılkaya Beji N, Yalçın 0. 2009. Effect of pelvic floor muscle exercises in the treatment of urinary incontinence during pregnancy and the postpartum period. Int Urogynecol J Pelvic Floor Dysfunct, 20: 1223-1231.

Dinç A. 2018. Prevalence of urinary incontinence during pregnancy and associated risk factors. Lower Urinary Tract 
Symp, 10: 303-307.

Dolan LM, Walsh D, Hamilton S. 2004. A study of quality of life in primigravidae with urinary incontinence. Int Urogynecol J, 15: 160-164.

Fitzgerald MP, Graziano, S. 2007. Anatomical and functional changes of the lower urinary tract during pregnancy. Urol Clin N Am, 34(1): 7-12.

Franco EM, Parés D, Colomé NL. 2014. Urinary incontinence during pregnancy: Is there a difference between first and third trimester? Eur J Obstet Gynecol Reprod Biol, 182: 8690.

Gökalp C, Okumuş H, Bilgiç D. 2020. Urinary incontinence and quality of life according to trimesters in pregnancy. Cukurova Med J, 45: 954-962.

Izci Y, Topsever P, Filiz TM, Cinar ND, Uludağ C, Lagro-Janssen T. 2009. The association between diabetes mellitus and urinary incontinence in adult women. Int Urogynecol J Pelvic Floor Dysfunct, 20: 947-952.

Jain P, Parsons M. 2011. The effects of obesity on the pelvic floor. Obs Gynae, 13: 133-142.

Kocaöz S, Talas MS, Atabekoğlu CS. 2010. Urinary incontinence in pregnant women and their quality of life. J Clin Nurs, 19: 3314-3323.

Kök G, Seven M, Guvenc G, Akyuz A. 2016. Urinary incontinence in pregnant women: prevalence, associated factors, and its effects on health-related quality of life. J Wound Ostomy Continence Nurs, 43: 511-516.

Liang CC, Chang SD, Lin SJ, Lin YJ. 2012. Lower urinary tract symptoms in primiparous women before and during pregnancy. Arch Gynecol Obstet, 285: 1205-1210.

Liu B, Wang L, Huang SS, Wu Q, Wu DL. 2014. Prevalence and risk factors of urinary incontinence among Chinese women in Shanghai. Int J Clin Exp Med, 7: 686-696.

Martins G, Soler ZA, Cordeiro JA, Amaro JL, Moore KN. 2010. Prevalence and risk factors for urinary incontinence in healthy pregnant Brazilian women. Int Urogynecol J, 21: 1271-1277.
Önder H. 2018. Nonparametric statistical methods used in biological experiments, BSJ Eng Sci, 1(1): 1-6.

Özdemir K, Şahin S, Özerdoğan N, Ünsal A. 2018. Evaluation of urinary incontinence and quality of life in married women aged between 20 and 49 years (Sakarya, Turkey). Turk J Med Sci, 23(48): 100-109.

Özerdoğan N, Kızılkaya Beji N. 2003. The prevalence and risk factors of urinary incontinence and its influence on the quality of life in 20 years or older of women in Eskişehir, Afyon, Kütahya, Bilecik cities. Florence Nightingale J Nurs, 13: 37-50.

Patrick DL, Martin ML, Bushnell DM. 1999. Cultural adaptation of a quality-of-life measure for urinary incontinence. European Urol, 36: 427-435.

Sangsawang B, Sangsawang, N. 2013. Stress urinary incontinence in pregnant women: a review of prevalence, pathophysiology, and treatment. Int Urogynecol J, 24: 901912.

Sangsawang B. 2014. Risk factors for the development of stress urinary incontinence during pregnancy in primigravidae: a review of the literature. Eur J Obstet Gynecol Reprod Biol, 178: 27-34.

Wanger TH, Patrick DL, Bavendam TG, Martin ML, Buesching DP. 1996. Quality of life in persons with urinary incontinence: development of a new measure. Urology, 47: 67-72.

Weidner AC, South, MM, Sanders DB, Stinnett SS. 2009. Change in urethral sphincter neuromuscular function during pregnancy persists after delivery. Am J Obstet Gynecol, 201(5): 521-526.

Wesnes SL, Rortveit G, Bø K, Hunskaar S. 2007. Urinary incontinence during pregnancy. Obstet Gynecol, 109: 922928.

Zhu L, Li L, Lang JH, Xu T. 2012. Prevalence and risk factors for peri and postpartum urinary incontinence in primiparous women in China: a prospective longitudinal study. Int Urogynecol J, 23: 563-572. 